\title{
Perioperative Exercise Therapy in Bariatric Surgery: Improving Patient Outcomes
}

This article was published in the following Dove Press journal:

Diabetes, Metabolic Syndrome and Obesity: Targets and Therapy

\author{
Sjaak Pouwels (iD) \\ Elijah E Sanches $\mathbb{B D}^{\prime}$ \\ Eylem Cagiltay (iD ${ }^{2}$ \\ Rich Severin (iD ${ }^{3-5}$ \\ Shane A Philips 5,6 \\ 'Department of Surgery, Haaglanden \\ Medical Center, The Hague, the \\ Netherlands; ${ }^{2}$ University of Health \\ Sciences Turkey, Sultan Abdulhamid Han \\ Education and Research Hospital, \\ Department of Endocrinology and \\ Metabolic Diseases, Istanbul, Uskudar, \\ 34668, Turkey; ${ }^{3}$ Department of Physical \\ Therapy, College of Applied Health \\ Sciences, University of Illinois at Chicago, \\ Chicago, IL, USA; ${ }^{4}$ Physical Therapy \\ Program, Robbins College of Health and \\ Human Sciences, Baylor University, \\ Waco, TX, USA; ${ }^{5}$ Graduate Program in \\ Rehabilitation Sciences, College of \\ Applied Health Sciences, University of \\ Illinois at Chicago, Chicago, IL, USA; \\ ${ }^{6}$ Department of Physical Therapy, \\ Integrative Physiologic Laboratory, \\ College of Applied Health Sciences, \\ University of Illinois at Chicago, Chicago, \\ IL, USA
}

\begin{abstract}
Nowadays, obesity and related comorbidities like type 2 diabetes, hypertension, dyslipidaemia and obstructive sleep apnoea syndrome are considered one of the medical challenges of the 21 st century. Even with the rise of bariatric and metabolic surgery, obesity and metabolic syndrome are reaching endemic proportions. Even in 2020, obesity is still a growing problem. There is increasing evidence that next to bariatric surgery, exercise interventions in the perioperative period could give extra beneficial effects. In this regard, effects on anthropometrics, cardiovascular risk factors and physical fitness. The aim of this review is to summarise effects of preoperative and postoperative exercise, tools for screening and directions for future research and implementations.
\end{abstract}

Keywords: obesity, exercise, bariatric surgery, metabolic surgery, postoperative outcomes

\section{Introduction}

Obesity and related comorbidities such as type 2 diabetes (T2DM), hypertension, dyslipidaemia and obstructive sleep apnoea syndrome (OSAS) are considered one of the medical challenges of the 21 st century. ${ }^{1,2}$ Even with the rise of bariatric and metabolic surgery, obesity and metabolic syndrome are reaching endemic proportions and the proportion of the population with morbid obesity increases every year. ${ }^{3}$ Dietary and exercise interventions alone are not entirely successful in reaching significant and longstanding weight loss. ${ }^{4,5}$ Bariatric surgery is the only treatment for patients with obesity that has a longstanding effect on weight loss and the (possible) remission of obesity-related comorbidities ${ }^{4,5}$ Despite these proven long-term effects, bariatric surgery is still a "tool" achieving long-term weight loss. Therefore, a significant amount of patients show weight regain after a few years. ${ }^{6}$ Several studies have shown that the combination of bariatric surgery and dietary/exercise interventions could be beneficial in maintaining weight loss in the long term. ${ }^{7,8}$ In our opinion, a pivotal aspect is good and well-structured follow-up program.

In other surgical specialties, exercise training is often used to improve preoperative physical fitness a postoperative outcomes. ${ }^{8-11}$ Despite promising beneficial outcomes these perioperative exercise programs are barely used in bariatric surgical practice. There is a significant body of evidence that indicates that exercise is good for improving physical fitness, but also Quality of Life (QoL). A Cochrane review by Shaw et $\mathrm{al}^{12}$ showed a reduction of $1.5 \mathrm{~kg}$ that was contributed to exercise. These findings were substantiated by a systematic review of Livhits et al. ${ }^{13}$ They focused on physical training and obesity and found a 4\% Excess Weight Loss (\%EWL) contributable to the exercise intervention. ${ }^{13}$ Similar findings were seen in the study by Egberts et al. ${ }^{14}$
Correspondence: Sjaak Pouwels Department of Surgery, Haaglanden Medical Center, P.O. Box 432, 250 I CK, The Hague, the Netherlands Email Sjaakpwls@gmail.com 
They found that exercise after bariatric surgery resulted in a body weight reduction of $3.6 \mathrm{~kg} .{ }^{14}$ However, there is still no consensus on how to structure exercise programs in bariatric surgery. Often only exercise advice is given without a structured program. ${ }^{12}$ Assessing outcome measurements, without a structured program is problematic, since weight loss measurements are self-reported and are not objectively assessed. Secondly, there is no adequate description of physical activity and which exercises were done. Recently Pouwels et $\mathrm{al}^{7}$ tried to summarise what kind of exercise is beneficial in the perioperative period (in bariatric surgery) and also when patients should exercise. They concluded that there is a positive effect of peri-bariatric exercise on anthropometrics, cardiovascular risk factors and physical fitness. However no unanimous conclusions could be drawn, since there was a high heterogeneity level among exercise programs. The aim of this review is to summarise effects of preoperative and postoperative exercise, tools for screening and directions for future research and implementations.

\section{Screening}

Surgery, in general, has considerable effects on patients with regards to complications, mortality and physical capacity/functioning. These risks are also present in patients with obesity and patient's before/after bariatric and metabolic surgery. To improve perioperative practices, improve logistics in the Operating Room and finally reduce complications and length of hospital stay the Enhanced Recovery after Surgery (ERAS) pathway was developed in the 1990s. ${ }^{15}$

These ERAS protocols were game changers in perioperative medicine and aimed to incorporate a multimodal and patient centred approach to surgical care. Initially developed for colorectal surgery, but it has been applied to all major surgical specialities. ${ }^{16}$ Also in primary and revisional bariatric surgery, extensive research has been done and ERAS or ERABS (Enhanced Recovery After Bariatric Surgery) has been implemented in the majority of hospitals worldwide. ${ }^{17-20}$ These care pathways were designed to modify physiological and psychological responses to surgical trauma by integrating a range of evidence-based components into a standardised clinical pathway. The most important aspect is that all these reductions (e.g. reduction in complications, reduced length of hospital stay and healthcare cost reduction) were achieved without comprising the perioperative patient safety ${ }^{21}$ and were associated with lower healthcare costs. ${ }^{22}$ Ljungqvist et $\mathrm{al}^{16}$ wrote a landmark paper and they studied and defined the 24 core aspects of the ERAS protocol. Among these essential elements are smoking and alcohol cessation, a structured preoperative information and education regimen, preoperative carbohydrate treatment and prophylaxis against venous thrombo-embolisms and infections. ${ }^{16}$

All these core ERAS aspects are implemented in the ERABS protocols and can also be easily used in perioperative exercise programs in patients scheduled for bariatric and metabolic surgery. These exercise interventions have similarities with a new concept of prehabilitation in other surgical practices. They have the goal of improving physical functioning of the patient to endure the upcoming surgical procedure. ${ }^{23}$ These concepts were developed according to a wide variety of studies that indicate that a higher preoperative level of fitness is associated with a reduction in postoperative complications and an improved clinical outcome. ${ }^{24-26}$

In this context, Orange et $\mathrm{al}^{27}$ and Minnella et $\mathrm{al}^{28}$ investigated and summarised the essential point for preparing patients for a surgical procedure. Among them; optimisation of nutritional status, psychological status and of course improving exercise capacity and physical functioning. Topal et $\mathrm{al}^{29}$ added one very important aspect, namely the improvement of comorbidities. This is essential since the bariatric surgical patients get older and have potentially more comorbidities with medication use. Table 1 gives an overview of the modifiable patient-related factors.

\section{Nutritional Assessment}

Malnutrition is a serious and impactful problem in surgical practice that affects approximately two out of three patients. ${ }^{30,31}$ We can state that malnutrition is a possibly undertreated condition that often leads to surgical and nonsurgical complications, in both the lean population and in patients with obesity. ${ }^{32-34}$ The physiological response due to surgical stress triggers a cascade of processes from systemic inflammation, insulin and blood glucose abnormalities, significant changes in energy expenditure and secretion of hormones. ${ }^{35,36}$ This can lead to significant clinical sequelae like poor appetite, weight loss, and muscle mass wasting, and could lead to cachexia or sarcopenia. ${ }^{35,36}$ These symptoms or sequelae will eventually lead to a higher risk of postoperative complications, extended hospital stay, higher mortality and morbidity rates and finally an increase health-care costs. ${ }^{35-37}$

Especially in the surgical oncology literature, there seems to be a clear relationship between nutrition, age, cancer, surgery and physical functioning. . $^{30,31,35,36,38}$ Therefore, nutritional assessment is an important part of bariatric surgical screening and prior to starting exercise programs. 
Table I Overview of the Modifiable Patient-Related Factors

\begin{tabular}{|c|c|}
\hline Component & Rationale \\
\hline Lifestyle Intervention & Reduce complications \\
\hline $\begin{array}{l}\text { Preoperative information, } \\
\text { education and counselling }\end{array}$ & Reduce fear and anxiety \\
\hline $\begin{array}{l}\text { Preoperative nutritional } \\
\text { status }\end{array}$ & $\begin{array}{l}\text { Optimising diet, reduce insulin } \\
\text { resistance }\end{array}$ \\
\hline Exercise intervention & $\begin{array}{l}\text { Improve physical fitness, reduce } \\
\text { complications, }\end{array}$ \\
\hline \multicolumn{2}{|c|}{$\begin{array}{l}\text { Adhering Enhanced Recovery After Bariatric Surgery } \\
\text { (ERABS) Principles }{ }^{18-20}\end{array}$} \\
\hline $\begin{array}{l}\text { I. Preoperative carbohydrate } \\
\text { treatment }\end{array}$ & I. Reduce insulin resistance \\
\hline $\begin{array}{l}\text { 2. Not routinely using bowel } \\
\text { preparation }\end{array}$ & $\begin{array}{l}\text { 2. Reduce dehydration, pro- } \\
\text { longed ileus and risk of ana- } \\
\text { stomotic leakage }\end{array}$ \\
\hline $\begin{array}{l}\text { 3. Prophylaxis against } \\
\text { thromboembolism }\end{array}$ & $\begin{array}{l}\text { 3. Reduce thromboembolic } \\
\text { complications }\end{array}$ \\
\hline 4. Antibiotic prophylaxis & 4. Reduce infection rate \\
\hline
\end{tabular}

\section{Physical Fitness Assessment}

The decrease in physical functioning due to obesity and the presence of comorbidities is an increasing worldwide problem. ${ }^{39}$ Physical/cardiorespiratory fitness (CRF) is a constant indicating the ability to meet the increase in oxygen consumption during daily activities, exercise and stress conditions. ${ }^{40-42}$ This can be impaired by, for example, obesity, cancer, surgery, radiotherapy, chemotherapy, infection or hormone therapy. ${ }^{7,43,44}$

A significant body of evidence has shown that the level of preoperative physical function is a significant predictor for postoperative complications and mortality. ${ }^{45-47}$ In light of this evidence, it has also been seen that a temporary functional decline is normal before, during and after hospitalization and after surgery. ${ }^{48}$ As stated earlier when these periods of inactivity prolong it has effects on muscle mass and the cardiopulmonary system. Eventually, muscle wasting will occur combined with possible cardiopulmonary deconditioning which will increase the risk of postoperative complications, mortality and psychological distress. These findings were substantiated by several studies of Kortebein et al. ${ }^{49-51}$ They have studied the effects of prolonged periods of bed rest on muscle strength of major muscle groups and not surprisingly they found that prolonged periods of bed rest lead to a significant decrease in muscle strength. Decreasing muscle strength was also seen after short periods of bed rest. All of the earlier mentioned phenomena could result in significant morbidity after surgery and therefore need to be optimised. ${ }^{50,52-54} \mathrm{In}$ general physical capacity predicts postoperative recovery, but seems to be more effects in frail and elderly patients undergoing major surgery. Therefore, nowadays there is an increasing interest in investigating a variety of PET and postoperative rehabilitation strategies ton optimise the surgical outcomes in this specific population. ${ }^{55-58}$ However, there is no "one size fits all", due to different patient characteristics, types of surgery and used programs (either PET or postoperative rehabilitation). ${ }^{59-61}$

We can now consider the effects of PET to treat/optimise perioperative care as a proof of concept. ${ }^{44}$ However, we still do not understand the effects in different patient populations and of course the cellular and immunological processes that exercise interventions induce in this matter. In other words, according to several studies in different surgical specialities its effectiveness can be difference. Especially in patients scheduled for orthopaedic knee or hip replacement surgery, there are some controversies regarding the effects of perioperative exercise interventions, especially PET. $^{62}$

Regarding types of exercise in these exercise interventions, the evidence is far from conclusive. Most of the studies investigate effects of aerobic training, ${ }^{63}$ however the combination of exercise types (for example, resistance and endurance training) can have even better effects. Unfortunately in perioperative medicine there is a lack of studies investigating these concepts, despite the cellular effects can be synergistic (with regards to tissue protein synthesis and aerobic capacity). ${ }^{64-66}$

Despite the fact that there is not much known about the physiological principles of exercise interventions in the perioperative period, clinicians should consider to get patients and exercise test prior to the start of an exercise intervention. Cardiopulmonary exercise testing (CPET) is considered to be the gold standard in exercise testing, however could also be costly and time consuming. ${ }^{40,67} \mathrm{CPET}$ is essential in determining the exercise tolerance of patients by indicating/calculating them in METs (Metabolic Equivalents of Time) ${ }^{40}$ One MET is defined as an oxygen use of $3.5 \mathrm{~mL} \mathrm{O} / \mathrm{kg} / \mathrm{min}$, which indicates the energy used while being seated in a resting position. ${ }^{40,41}$ Climbing a flight of stairs or walking up a hill are activities associated with METs $>4$, and they are considered a "safe" threshold below which postoperative complications are more likely to occur. ${ }^{68}$ 


\section{Psychological Status and Improvement of Comorbidities}

Psychological distress is an often-overlooked problem that can have a significant effect on the postoperative convalescence of patients. In general, there are high rates of anxiety, depression and associated disorders in the surgical population. ${ }^{69}$ It is known that psychological distress in the form of anxiety and depressive disorders can have a negative impact on wound healing, infection rate, length of hospital stay and adherence to medical treatment, despite that the pathophysiological mechanism is still largely unknown. ${ }^{70-73}$ A study by Mitchell et al. ${ }^{74}$ showed that anxiety disorders should be treated in the perioperative period to improve postoperative outcomes. Therefore, a psychologist should also be incorporated in the multidisciplinary team.

With the increasing age of surgical patients, but also patients scheduled for bariatric surgery, ${ }^{75}$ we need to take into account the presence of comorbidities. It is well known that extensive comorbid conditions are present in the majority of patients that undergo abdominal, bariatric, thoracic and cardiovascular surgery. High rates of coronary disease or congestive heart failure ( $>50 \%)$, hypertension $(30-50 \%)$, COPD (30-40\%) and chronic renal disease (5\%) are seen in the surgical patient population. ${ }^{76-78}$ The presence of these comorbidities can have a significant impact on postoperative recovery and the occurrence of functional decline after surgery. Therefore, efforts should be made to optimize these conditions prior to surgery. This might be the case in patients with cancer, COPD and heart failure. ${ }^{59,60,79}$

The burden of these morbidities should also be considered following bariatric surgery. A population-based study by Moonesinghe et al. ${ }^{80}$ investigated the burden of postoperative morbidity on overall survival and they showed a significant impact in a variety of surgical specialties. ${ }^{80}$ There must be a place for the optimisation of comorbid conditions (e.g. COPD, heart failure). Optimisation of medication use and/or lifestyle interventions could be incorporated in such a strategy. ${ }^{10}$

\section{Preoperative Exercise Therapy}

In general, there are very few data on the effectiveness of specific preoperative exercise therapy programs on CRF and functional performance following surgery. Some of the literature has been summarised by Pouwels et al. ${ }^{7}$ regarding its effects and perioperative timing.

In general for both the preoperative and postoperative there is no consensus what to do in terms of exercise interventions. Baillot et al. ${ }^{81}$ studied a preoperative exercise program with 35 supervised exercise sessions in 12 weeks. In total seven patients completed the full program and five of them had their bariatric surgery before the end of the program. The corresponding attendance rates were a median of $57.3 \%$ (32.5-77.6\%). Significant weight and BMI reduction, reduction in neck circumference and fat mass were achieved (respectively; before; $144.3 \mathrm{~kg}$, after; 140.2, $\mathrm{p}=0.07$; before; $51.4 \mathrm{~kg} / \mathrm{m}^{2}$, after; $47.2 \mathrm{~kg} / \mathrm{m}^{2}$, $\mathrm{p}=0.004$; before; $42.2 \mathrm{~cm}$, after; $41.0 \mathrm{~cm}, \mathrm{p}=0.016$ and before; $72.1 \mathrm{~kg}$, after; $69.1 \mathrm{~kg}, \mathrm{p}=0.026$ ). After the exercise program, several physical fitness measures increased significantly (six-minute walk test distance, time of the half-squat test and number of flexion during the arm curl test ${ }^{81}$ This resulted in a high satisfaction with the intervention and the advice given by exercise professionals resulting in a significant improvement in the total HealthRelated Quality Of Life (HRQOL) after the exercise intervention $(\mathrm{p}=0.012){ }^{81}$

With regards to anthropometric measurements, the study by Funderburk et al. ${ }^{82}$ showed similar results (a reduction in body weight after 12 weeks supervised aquatic exercises of $5.0 \mathrm{~kg}$ in the intervention group compared with $2.3 \mathrm{~kg}$ in the control group). ${ }^{82}$ Six-minute walking test distance increased with $10.4 \mathrm{~m}$, but in the control group it increased with $40.2 \mathrm{~m}$ (after 12 weeks of aquatic exercises). ${ }^{82}$ HRQOL measurements were not significantly different between the intervention group and the control group. Bodily pain (as a sub-item of the Short Form 36 (SF-36) questionnaire) and depression scores (Beck Depression inventory) after 12 weeks decreased significantly $(\mathrm{p}<0.05){ }^{82}$

Hickey et al ${ }^{83}$ investigated a seven-day exercise training scheme consisting of 60 minute sessions once a day. They found no significant change in anthropometric variables (body weight and fat-free mass, but they did find a significant decrease in fasting plasma insulin $(-41.7 \mathrm{pM})$. Strangely enough, there were not any corresponding changes in blood glucose levels and blood lipid concentrations. ${ }^{83}$ Also, no significant differences were found in maximal oxygen uptake (which was measured by $\mathrm{VO}_{2}$ peak). ${ }^{83}$

The findings of the study of Marcon et al. ${ }^{84}$ corresponded with the tendency found in previous studies. They investigated 24 weeks supervised low intensity endurance training and found significant changes in anthropometric variables; body weight $(-5.3 \mathrm{~kg}(\mathrm{p}<0.001))$ and BMI $(-1.9 \mathrm{~kg} / \mathrm{m} 2$ $(p<0.001))$ decreased significantly. Also, significant decrease in systolic and diastolic blood pressure $(-23.8 \mathrm{mmHg}$ 
$(\mathrm{p}=0.007)$ and $-14.4 \mathrm{mmHg}(\mathrm{p}=0.001)$ respectively $)$ was found $^{84}$ Finally, significant improvements were seen in blood lipid and glucose concentration and in six minute walking test distance $(+69.8 \mathrm{~m}(\mathrm{p}<0.0001))$ after 24 weeks exercise intervention. ${ }^{84}$

The Bari-Active trial from Bond et al. ${ }^{85}$ showed that an exercise intervention in the period six weeks prior to bariatric surgery has a significant improvement on physical activity patterns compared to the standard care group. These results were supported by a randomized controlled trial by Marcon et al. ${ }^{86}$ that showed a 4 month, twice weekly supervised program of low-intensity physical exercise can be valuable in the perioperative bariatric care.

\section{Postoperative Exercise Therapy}

In postoperative rehabilitation or postoperative exercise therapy in bariatric surgery, there are few studies that test the effectiveness of different exercise modes on outcomes. Further, the outcome measures appear to be heterogeneous. ${ }^{7,85,87,88}$

Stegen et al. ${ }^{89}$ investigated a 16 weeks postoperative exercise program after Roux en Y Gastric Bypass (GB) surgery. In this study, postoperative patients that completed the exercise program $(\mathrm{GB}+\mathrm{E})$ were compared with patients that only had GB surgery. Both groups had the same extent of weight loss and changes in other anthropometrics after four months $(\mathrm{GB}=-26.6 \pm 14.6 \mathrm{~kg}$; $\mathrm{GB}+\mathrm{E}=$ $-22.7 \pm 5.7 \mathrm{~kg})$, BMI $\left(\mathrm{GB}=-8.3 \pm 4.1 \mathrm{~kg} / \mathrm{m}^{2} ; \mathrm{GB}+\mathrm{E}=\right.$ $\left.-8.1 \pm 2.5 \mathrm{~kg} / \mathrm{m}^{2}\right)$ and waist circumference $(\mathrm{GB}=-20.3 \pm$ $11.6 \mathrm{~cm} ; \mathrm{GB}+\mathrm{E}=-17.2 \pm 8.1 \mathrm{~cm}) .{ }^{89}$

In terms of exercise capacity, which was measured as ventilator anaerobic threshold (VAT) using a maximal bicycle ergometer, there were no significant differences. Both groups reached their VAT at the power (GB $=93 \pm 24$ $\mathrm{W} ; \mathrm{GB}+\mathrm{E}=90 \pm 24 \mathrm{~W}$ ) with an equal time of occurrence $(\mathrm{GB}=270 \pm 107 \mathrm{~s} ; \mathrm{GB}+\mathrm{E}=266 \pm 133 \mathrm{~s}) .{ }^{89}$ Both groups showed no differences in peak exercise parameters (preoperative versus postoperatively; respectively peak oxygen uptake of $17.4 \pm 4.9 \mathrm{~mL} / \mathrm{kg} / \mathrm{min}(\mathrm{GB})$ and $17.6 \pm 3.2 \mathrm{~mL} /$ $\mathrm{kg} / \mathrm{min}(\mathrm{GB}+\mathrm{E}))^{89}$

However, the exercise training intervention showed promising effects regarding muscle loss after bariatric surgery. The untrained patients, who only had bariatric surgery showed a decrease in dynamic muscle strength (a decrease of $16 \%$ in quadriceps strength, 36\% biceps strength and 39\% triceps strength). ${ }^{89}$ Patients who had an exercise program after gastric bypass surgery $(\mathrm{GB}+\mathrm{E})$ prevented this decrease. ${ }^{89}$ Regarding static muscle strength (measured as handgrip strength, both groups had a decrease (respectively $18 \%$ and $7 \%$ ). ${ }^{89}$

Castello-Simoes et al. ${ }^{90}$ investigated a three group 12 week post-bariatric exercise intervention, 1) a trained group (TG), 2) a eutrophic group (EG) and 3) a control group (CG).

Anthropometric changes were consistent with other studies and the TG and CG group showed significant weight reduction after 4 months. Also, both groups (TG and CG) showed a similar significant increase in the 6-minute walking test distance $(6 \mathrm{MWT})^{90}$ Finally a significant increase of the predicted forced vital capacity (pFVC) was found (before: $94.0 \pm 3.1$; after: $101.0 \pm 2.5$ ) in TG and a significant reduction in dyspnoea scores was found in the same group 4 months after bariatric surgery (before: $5.8 \pm 0.6$; after $2.7 \pm 0.8$ ).$^{90}$ Shah et al. ${ }^{91}$ found similar results regarding weight loss after a high volume exercise program in 20 patients for 12 weeks. Interestingly, theyfound no difference in cardiovascular risk factors after compared to the control group. ${ }^{91}$

Berggren et al performed a study on skeletal muscle lipid oxidation before and after 10 days of endurance training in post-bariatric patients. ${ }^{92}$ Not surprisingly, they found significant weight loss after the exercise intervention. ( $p$ $<0.05) .{ }^{92}$ Fatty acid oxidation in the muscle was not significantly different between patients with morbid obesity compared to the weight loss groups. Compared to lean individuals the oxidation of fatty acids was depressed $(-45 \% ; \mathrm{P}<0.05)$. In contrast, ten days of exercise training increased fatty acid oxidation in the skeletal muscle of lean, obese and previously extreme obese subjects after weight loss (respectively +1.7 -fold, +1.8 -fold and +2.6 -fold). ${ }^{92}$ These data suggest that there is reversibility of cellular oxidation processes through exercise interventions in patients after bariatric surgery.

Marc-Hernandez et $\mathrm{al}^{93}$ investigated the effects of a high-intensity exercise program has the ability to reduce weight regain three years after bariatric surgery. Twentyone patients that had a sleeve gastrectomy three years ago were randomised in an exercise group that performed a 5-month supervised exercise program, compared to a control group that followed usual care. ${ }^{93}$ Body anthropometrics, physical fitness and cardiovascular parameters were collected before and after the training program. After the program, the exercise group showed to have significant reductions in fat mass, glycaemia and blood cholesterol levels. The control group showed an increase in body weight and fast mass. Two months after finalising the 
exercise program, the patients who had the exercise intervention showed similar results as the control group during the study. In particular, an increase in body weight and fat mass and higher blood glucose and cholesterol levels, compared to directly after the exercise program. ${ }^{93}$ This rebound effect might be due to exercise beliefs and exercise patterns that do not change after bariatric surgery. This was substantiated by a recent study done by Ouellette et al. ${ }^{94}$ They found that in the postoperative period, moderate-to-vigorous physical activity (MVPA) patterns did not significantly change, despite patients expectations. $^{94}$ Is this context there might also be a behavioural component that can be treated. ${ }^{94}$

The data of the mentioned studies show that there might be beneficial effects on physical activity measurements, quality of life and traditional risk factors. In addition, it is important for future studies to take into account the metabolic effects of the surgical procedures prior to exercise and lifestyle interventions. ${ }^{6,95}$ Hopefully, future initiatives will be able to answer these important questions. ${ }^{96,97}$

\section{Discussion}

In surgical practice, perioperative exercise interventions seem to get more and more attention, due to beneficial effects on complication rate and patient convalescence. Also with the introduction of prehabilitation programs ${ }^{8-11,29}$ and their promising results in various surgical fields it is surprising that exercise interventions in bariatric surgery are so sparsely investigated. In the studies that investigate these perioperative exercise programs, there seems to be a beneficial effect on weight loss parameters, physical activity measurements and risk factors for cardiovascular diseases. However due to heterogeneous study designs, possible under powering and the lack of structured exercise training programs, no definitive conclusion can be drawn. All these factors hamper practical guidance and implementation in clinical practice.

Table 2 gives an overview of the common findings in the studies assessing exercise interventions in bariatric surgery. Figure 1 gives a conceptual framework of perioperative exercise interventions in bariatric surgery. The heterogeneity of exercise programs makes comparisons difficult and according to several studies it is not evident as to what the optimal exercise programs should be and what the timing should be around bariatric surgery. ${ }^{7}$

In general, it can be stated that exercise has beneficial total body effects. More specifically tremendous effects can be present in body composition changes, better blood pressure control, increase in insulin sensitivity, decrease of inflammation and presence of "inflammation" biomarkers and also subclinical carotid atherosclerosis (measured as Carotid Intima Media Thickness (CIMT)). The effects of exercise have been associated with physiological changes in the human cardiovascular system, for example removal of oxidized phospholipids from the vessel wall, stabilisation of atherosclerosis and positive changes in LDL cholesterol. ${ }^{98}$

These physiological changes correlated strongly with improvement of vascular function and in improvement of atherosclerosis (e.g. decreased burden of atherosclerosis). ${ }^{99}$

The evidence from the ARBITER 6 trial showed that exercise is superior in inducing these beneficial effects compared to medical treatment (with either statins or niacin). ${ }^{100}$ In other words, exercise training should be a part of every medical intervention or perioperative rehabilitations program. ${ }^{101}$

Despite a very large body of evidence that bariatric surgery is a longstanding intervention with great effects on

Table 2 Summary of Exercise Programs, Intensity, Duration, Supervision and Perioperative Timing

\begin{tabular}{|c|c|c|c|c|c|c|c|c|c|c|}
\hline & $\begin{array}{l}\text { Shah } \\
\text { et al. }{ }^{91}\end{array}$ & $\begin{array}{l}\text { Castello- } \\
\text { Simoes et al. }{ }^{90}\end{array}$ & $\begin{array}{l}\text { Stegen } \\
\text { et al. }{ }^{89}\end{array}$ & $\begin{array}{l}\text { Baillot } \\
\text { et al. }{ }^{81}\end{array}$ & $\begin{array}{l}\text { Funderburk } \\
\text { et al. }{ }^{82}\end{array}$ & $\begin{array}{l}\text { Berggren } \\
\text { et al. }{ }^{92}\end{array}$ & $\begin{array}{l}\text { Hickey } \\
\text { et al. }^{83}\end{array}$ & $\begin{array}{l}\text { Marcon } \\
\text { et al. }^{84}\end{array}$ & $\begin{array}{l}\text { Bond } \\
\text { et al. }{ }^{85}\end{array}$ & $\begin{array}{l}\text { Marcon } \\
\text { et al. }{ }^{86}\end{array}$ \\
\hline $\begin{array}{l}\text { Duration } \\
\text { (weeks) }\end{array}$ & 12 & 12 & 16 & 12 & 12 & 2 & I & 24 & 6 & 16 \\
\hline Intensity & $\begin{array}{l}60-70 \% \\
\mathrm{VO}_{2} \max \end{array}$ & $60-70 \% \mathrm{HR}$ & $\begin{array}{l}60-75 \% \\
\text { HR/RM }\end{array}$ & $\begin{array}{l}55-85 \% \\
\text { of HRR }\end{array}$ & $x$ & $\begin{array}{l}70 \% \mathrm{VO}_{2} \\
\max \end{array}$ & $\begin{array}{l}65 \% \mathrm{VO}_{2} \\
\text { peak }\end{array}$ & $x$ & $x$ & $\begin{array}{l}\text { Low (not } \\
\text { specified) }\end{array}$ \\
\hline Supervision & Partial & Whole & Whole & Partial & Whole & $x$ & Whole & Whole & $x$ & Whole \\
\hline $\begin{array}{l}\text { Timing } \\
\text { bariatric } \\
\text { surgery }\end{array}$ & Post & Post & Post & Pre & Pre & Post & Pre & Pre & Pre & Pre \\
\hline
\end{tabular}

Abbreviations: HR, heart rate; HRR, heart rate reserve; RM, repeated measurements; $2 \mathrm{KmWT}$, 2 kilometer walking test; $x$, unknown. 


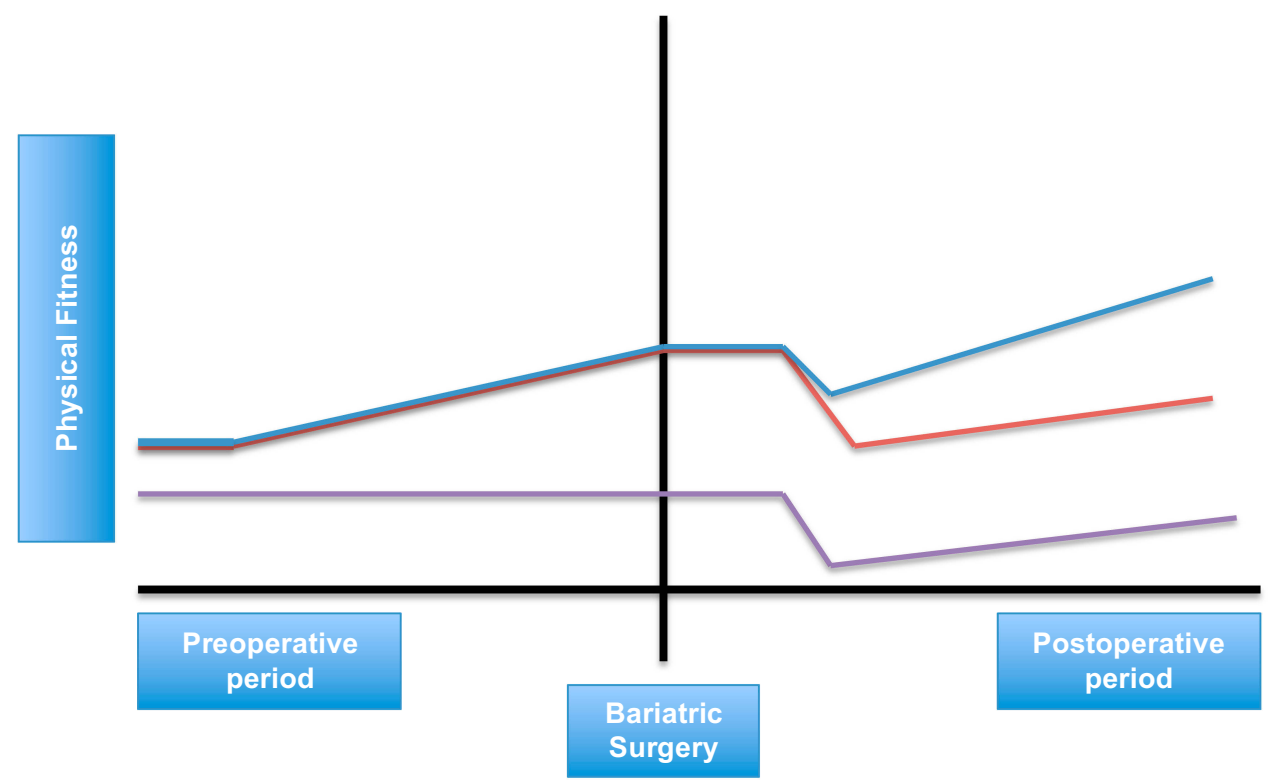

Figure I Conceptual framework of perioperative exercise interventions in bariatric surgery. Purple line: patients who do not receive any perioperative exercise intervention. Orange line: patients who only receive preoperative exercise training. Blue line: patients who receive preoperative and postoperative exercise training.

the human body, it needs to be said that it also has consequences. One of them is muscle loss or otherwise called "muscle wasting", which was showed in the study by Stegen et al. ${ }^{89}$ This can be explained by the rapid weight loss after bariatric surgery. In the study by Stegen et al the untrained (GB) group lost approximately $7.6 \mathrm{~kg}$ of muscle mass, which is $29.7 \%$ of the total body weight lost $(-26.6 \mathrm{~kg})^{89}$ Dieting, exercise interventions and also bariatric surgery results in the loss of fat-free mass. This was confirmed by studies done by Stiegler et al. ${ }^{102}$ and Chaston et al. ${ }^{103}$ They showed that there is a positive correlation between weight loss and fat-free mass loss (FFML). Very low caloric diets result in a greater FFML compared to moderate caloric diets. Bariatric surgery results in greater FFML than very low caloric diets.

A study by Webster et al. ${ }^{104}$ showed that there is a limit of FFML after bariatric surgery which is approximately $22 \%$ of the total weight loss. This is because of the functions of the muscle in resting metabolic rate, thermoregulation, oxidative capacity of the body and weight management. Exercise training can attenuate muscle atrophy and can maintain FFM during weight loss, ${ }^{102,103}$ but the value of a perioperative exercise program for bariatric surgery has not been investigated.

It is not clear whether or not there is a decrease of muscle strength contributes to poor health outcomes or risk after weight loss surgery. It is well known that obese individuals have higher absolute muscle strength compared to lean subjects, but there is lower relative muscle strength in terms of total body weight. ${ }^{105-108}$ This gives patients an impaired functional capacity, which results in the fact that more strength is needed to handle a heavier body. Therefore, it might be important to prevent a decrease in muscle strength after bariatric surgery.

\section{Conclusion}

We can state that perioperative exercise programs in bariatric surgery might have beneficial effects on weight loss parameters, physical activity measurements and risk factors for cardiovascular diseases. However, the heterogeneity of exercise programs makes comparisons difficult and according to several studies reviewed in this paper it is not evident as to what the optimal exercise programs should be and what the timing should be around bariatric surgery. Future studies focused on the effectiveness of exercise intervention mode, intensity and timing before or after bariatric surgery to maximize cardiorespiratory fitness, physical function and reductions in cardiometabolic risk appears evident.

\section{Author Contributions}

All authors made substantial contributions to conception and design, acquisition of data, or analysis and interpretation of data; took part in drafting the article or revising it critically for important intellectual content; gave final approval of the version to be published; and agree to be accountable for all aspects of the work. 


\section{Disclosure}

The authors report no conflicts of interest in this work.

\section{References}

1. Obesity: preventing and managing the global epidemic. Report of a WHO consultation. World Health Organization technical report series. 2000;894:i-xii,1-253.

2. Tjepkema M. Adult obesity. Health Rep. 2006;17(3):9-25.

3. Sturm R. Increases in morbid obesity in the USA: 2000-2005. Public Health. 2007;121(7):492-496. doi:10.1016/j.puhe.2007.01.006

4. Picot J, Jones J, Colquitt JL, et al. The clinical effectiveness and cost-effectiveness of bariatric (weight loss) surgery for obesity: a systematic review and economic evaluation. Health Technol Assess. 2009;13(41):1-190, 215-357, iii-iv.

5. Colquitt JL, Picot J, Loveman E, Clegg AJ. Surgery for obesity. Cochrane Database Syst Rev. 2009;2:CD003641.

6. Buchwald $\mathrm{H}$. The evolution of metabolic/bariatric surgery. Obes Surg. 2014;24(8):1126-1135. doi:10.1007/s11695-014-1354-3

7. Pouwels S, Wit M, Teijink JA, Nienhuijs SW. Aspects of exercise before or after bariatric surgery: a systematic review. Obes Facts. 2015;8(2):132-146. doi:10.1159/000381201

8. Pouwels S, Stokmans RA, Willigendael EM, et al. Preoperative exercise therapy for elective major abdominal surgery: a systematic review. Int $J$ Surg. 2014;12(2):134-140. doi:10.1016/j.ijsu.2013.11.018

9. Pouwels S, Hageman D, Gommans LN, et al. Preoperative exercise therapy in surgical care: a scoping review. J Clin Anesth. 2016;33:476-490. doi:10.1016/j.jclinane.2016.06.032

10. Pouwels S, Fiddelaers J, Teijink JA, Woorst JF, Siebenga J, Smeenk FW. Preoperative exercise therapy in lung surgery patients: a systematic review. Respir Med. 2015;109 (12):1495-1504. doi:10.1016/j.rmed.2015.08.009

11. Pouwels S, Willigendael EM, van Sambeek MR, Nienhuijs SW, Cuypers PW, Teijink JA. Beneficial effects of pre-operative exercise therapy in patients with an abdominal aortic aneurysm: a systematic review. Eur J Vasc Endovasc Surg. 2015;49 (1):66-76.

12. Shaw K, Gennat H, O'Rourke P, Del Mar C. Exercise for overweight or obesity. Cochrane Database Syst Rev. 2006;4):CD003817.

13. Livhits M, Mercado C, Yermilov I, et al. Exercise following bariatric surgery: systematic review. Obes Surg. 2010;20 (5):657-665. doi:10.1007/s11695-010-0096-0

14. Egberts K, Brown WA, Brennan L, O'Brien PE. Does exercise improve weight loss after bariatric surgery? A systematic review. Obes Surg. 2012;22(2):335-341. doi:10.1007/s11695-011-0544-5

15. Kehlet H. Multimodal approach to control postoperative pathophysiology and rehabilitation. Br J Anaesth. 1997;78(5):606-617. doi:10.1093/bja/78.5.606

16. Ljungqvist $\mathrm{O}$, Scott $\mathrm{M}$, Fearon KC. Enhanced recovery after surgery: a review. JAMA Surg. 2017;152(3):292-298. doi:10.1001/jamasurg.2016.4952

17. Ruiz-Tovar J, Sanchez-Santos R, Martin-Garcia-Almenta E, et al. Enhanced recovery after bariatric surgery. Cir Esp. 2019;97 (10):551-559. doi:10.1016/j.ciresp.2019.05.003

18. Geubbels N, Evren I, Acherman YIZ, et al. Randomized clinical trial of an enhanced recovery after surgery programme versus conventional care in laparoscopic Roux-en-Y gastric bypass surgery. BJS Open. 2019;3(3):274-281. doi:10.1002/bjs5.50143

19. Mannaerts GHH, Allatif REA, Al Hashmi FY, et al. First successful large-scale introduction of an Enhanced Recovery after Bariatric Surgery (ERABS) program in the Middle East: the results and lessons learned of Tawam Hospital/Johns Hopkins, a Tertiary Governmental Center in the UAE. Obes Surg. 2019;29 (7):2100-2109. doi:10.1007/s11695-019-03841-4
20. Trotta M, Ferrari C, D'Alessandro G, Sarra G, Piscitelli G, Marinari GM. Enhanced recovery after bariatric surgery (ERABS) in a high-volume bariatric center. Surg Obes Relat Dis. 2019;15(10):1785-1792. doi:10.1016/j.soard.2019.06.038

21. Varadhan KK, Neal KR, Dejong CH, Fearon KC, Ljungqvist O, Lobo DN. The enhanced recovery after surgery (ERAS) pathway for patients undergoing major elective open colorectal surgery: a meta-analysis of randomized controlled trials. Clin Nutr. 2010;29 (4):434-440. doi:10.1016/j.clnu.2010.01.004

22. Roulin D, Donadini A, Gander S, et al. Cost-effectiveness of the implementation of an enhanced recovery protocol for colorectal surgery. Br J Surg. 2013;100(8):1108-1114. doi:10.1002/bjs.9184

23. Topp R, Ditmeyer M, King K, Doherty K, Hornyak J 3rd. The effect of bed rest and potential of prehabilitation on patients in the intensive care unit. AACN Clin Issues. 2002;13:263-276. doi:10.1097/00044067-200205000-00011

24. Wilson RJ, Davies S, Yates D, Redman J, Stone M. Impaired functional capacity is associated with all-cause mortality after major elective intra-abdominal surgery. Br J Anaesth. 2010;105 (3):297-303. doi:10.1093/bja/aeq128

25. Thompson AR, Peters N, Lovegrove RE, et al. Cardiopulmonary exercise testing provides a predictive tool for early and late outcomes in abdominal aortic aneurysm patients. Ann R Coll Surg Engl. 2011;93(6):474-481. doi:10.1308/003588411X587235

26. Young EL, Karthikesalinam A, Huddart S, et al. A systematic review of the role of cardiopulmonary exercise testing in vascular surgery. Eur J Vasc Endovasc Surg. 2012;44(1):64-71. doi:10.1016/j.ejvs.2012.03.022

27. Orange ST, Northgraves MJ, Marshall P, Madden LA, Vince RV. Exercise prehabilitation in elective intra-cavity surgery: a role within the ERAS pathway? A narrative review. Int $J$ Surg. 2018;56:328-333. doi:10.1016/j.ijsu.2018.04.054

28. Minnella EM, Carli F. Prehabilitation and functional recovery for colorectal cancer patients. Eur J Surg Oncol. 2018;44 (7):919-926. doi:10.1016/j.ejso.2018.04.016

29. Topal B, Smelt HJM, Van Helden EV, et al. Utility of preoperative exercise therapy in reducing postoperative morbidity after surgery; a clinical overview of current evidence. Expert Rev Cardiovasc Ther. 2019;17(6):395-412. doi:10.1080/ 14779072.2019 .1625771

30. Planas M, Alvarez-Hernandez J, Leon-Sanz M, Celaya-Perez S, Araujo K, Garcia de Lorenzo A. Prevalence of hospital malnutrition in cancer patients: a sub-analysis of the PREDyCES(R) study. Support Care Cancer. 2016;24(1):429-435. doi:10.1007/ s00520-015-2813-7

31. Blanc-Bisson C, Fonck M, Rainfray M, Soubeyran P, BourdelMarchasson I. Undernutrition in elderly patients with cancer: target for diagnosis and intervention. Crit Rev Oncol Hematol. 2008;67(3):243-254. doi:10.1016/j.critrevonc.2008.04.005

32. Wells JC, Sawaya AL, Wibaek R, et al. The double burden of malnutrition: aetiological pathways and consequences for health. Lancet. 2019.

33. Popkin BM, Corvalan C, Grummer-Strawn LM. Dynamics of the double burden of malnutrition and the changing nutrition reality. Lancet. 2019.

34. Raoult D. Microbiota, obesity and malnutrition. Microb Pathog. 2017;106:1-2. doi:10.1016/j.micpath.2016.02.001

35. Aaldriks AA, van der Geest LG, Giltay EJ, et al. Frailty and malnutrition predictive of mortality risk in older patients with advanced colorectal cancer receiving chemotherapy. J Geriatr Oncol. 2013;4(3):218-226. doi:10.1016/j.jgo.2013.04.001

36. Maasberg S, Knappe-Drzikova B, Vonderbeck D, et al. Malnutrition predicts clinical outcome in patients with neuroendocrine neoplasia. Neuroendocrinology. 2017;104(1):11-25. doi: $10.1159 / 000442983$ 
37. Heriot AG, Tekkis PP, Smith JJ, et al. Prediction of postoperative mortality in elderly patients with colorectal cancer. Dis Colon Rectum. 2006;49(6):816-824. doi:10.1007/s10350-006-0523-4

38. Awad S, Lobo DN. What's new in perioperative nutritional support? Curr Opin Anaesthesiol. 2011;24(3):339-348. doi:10.1097/ ACO.0b013e328345865e

39. Blair SN. Physical inactivity: the biggest public health problem of the 21st century. Br J Sports Med. 2009;43(1):1-2.

40. Nelson N, Asplund CA. Exercise testing: who, when, and why? PM R. 2016;8(3 Suppl):S16-S23. doi:10.1016/j.pmrj.2015.10.019

41. Leclerc K. Cardiopulmonary exercise testing: a contemporary and versatile clinical tool. Cleve Clin J Med. 2017;84(2):161-168. doi:10.3949/ccjm.84a.15013

42. Mueller MJ, Maluf KS. Tissue adaptation to physical stress: a proposed "physical stress theory" to guide physical therapist practice, education, and research. Phys Ther. 2002;82 (4):383-403. doi:10.1093/ptj/82.4.383

43. Jones LW, Liang Y, Pituskin EN, et al. Effect of exercise training on peak oxygen consumption in patients with cancer: a meta-analysis. Oncologist. 2011;16(1):112-120. doi:10.1634/ theoncologist.2010-0197

44. Jones LW, Eves ND, Haykowsky M, Freedland SJ, Mackey JR. Exercise intolerance in cancer and the role of exercise therapy to reverse dysfunction. Lancet Oncol. 2009;10(6):598-605. doi:10.1016/S1470-2045(09)70031-2

45. Thombs BD, Ziegelstein RC, Stewart DE, Abbey SE, Parakh K, Grace SL. Physical health status assessed during hospitalization for acute coronary syndrome predicts mortality 12 months later. J Psychosom Res. 2008;65(6):587-593. doi:10.1016/j.jpsychores. 2008.06.004

46. Tosteson AN, Gottlieb DJ, Radley DC, Fisher ES, Melton LJ 3rd Excess mortality following hip fracture: the role of underlying health status. Osteoporos Int. 2007;18(11):1463-1472. doi:10.1007/s00198-007-0429-6

47. Cesari M, Onder G, Zamboni V, et al. Physical function and self-rated health status as predictors of mortality: results from longitudinal analysis in the ilSIRENTE study. BMC Geriatr. 2008;8:34. doi:10.1186/1471-2318-8-34

48. Patel BK, Hall JB. Perioperative physiotherapy. Curr Opin Anaesthesiol. 2013;26(2):152-156. doi:10.1097/ACO.0b013e32 $835 \mathrm{e} 8 \mathrm{~b} 34$

49. Functional impact of ten days of bed rest in healthy older adults. Nurs Older People. 2017;29(5):13. doi:10.7748/nop.29.5.13.s15

50. Kortebein P. Rehabilitation for hospital-associated deconditioning. Am J Phys Med Rehabil. 2009;88(1):66-77. doi:10.1097/PHM.0b013e3181838f70

51. Kortebein P, Symons TB, Ferrando A, et al. Functional impact of 10 days of bed rest in healthy older adults. J Gerontol a Biol Sci Med Sci. 2008;63(10):1076-1081. doi:10.1093/gerona/63. 10.1076

52. Bajotto G, Shimomura Y. Determinants of disuse-induced skeletal muscle atrophy: exercise and nutrition countermeasures to prevent protein loss. J Nutr Sci Vitaminol (Tokyo). 2006;52 (4):233-247. doi:10.3177/jnsv.52.233

53. Chetta A, Tzani P, Marangio E, Carbognani P, Bobbio A, Olivieri D. Respiratory effects of surgery and pulmonary function testing in the preoperative evaluation. Acta Biomed. 2006;77 (2):69-74.

54. Walton-Geer PS. Prevention of pressure ulcers in the surgical patient. AORN J. 2009;89(3):538-48; quiz 49-51. doi:10.1016/j. aorn.2008.12.022

55. Arozullah A, Khuri S, Henderson W, Daley J. Development and validation of a multifactorial risk index for predicting postoperative pneumonia after major noncardiac surgery. Ann Intern Med. 2001;135:847-857. doi:10.7326/0003-4819-135-10-20011120000005
56. Biccard B. Relationship between the inability to climb two flights of stairs and outcome after major non-cardiac surgery: implications for the pre-operative assessment of functional capacity. Anaesthesia. 2005;60:588-593. doi:10.1111/j.1365-2044.2005.04181.x

57. Brutsche M, Spiliopoulos A, Bolliger C, Licker M, Frey J, Tschopp J. Exercise capacity and extent of resection as predictors or surgical risk in lung cancer. Eur Respir J. 2000;15:828-832. doi:10.1034/j.1399-3003.2000.15e03.x

58. Michota F, Frost S. The preoperative evaluation: use the history and physical rather than routine testing. Cleve Clin J Med. 2004;71:63-70. doi:10.3949/ccjm.71.1.63

59. Halloway S, Buchholz SW, Wilbur J, Schoeny ME. Prehabilitation interventions for older adults: an integrative review. West J Nurs Res. 2015;37(1):103-123. doi:10.1177/0193945914551006

60. Spruit MA, Singh SJ, Garvey C, et al. An official American Thoracic Society/European Respiratory Society statement: key concepts and advances in pulmonary rehabilitation. Am J Respir Crit Care Med. 2013;188(8):e13-e64. doi:10.1164/rccm.2013091634ST

61. Valkenet K, van de Port I, Dronkers J, de Vries W, Lindeman E, Backx F. The effects of preoperative exercise therapy on postoperative outcome: a systematic review. Clin Rehabil. 2011;25:99-111. doi:10.1177/0269215510380830

62. Powers SK, Jackson MJ. Exercise-induced oxidative stress: cellular mechanisms and impact on muscle force production. Physiol Rev. 2008;88(4):1243-1276. doi:10.1152/physrev.00031.2007

63. Chodzko-Zajko WJ, Proctor DN, Fiatarone Singh MA, et al. American College of Sports Medicine position stand. Exercise and physical activity for older adults. Med Sci Sports Exerc. 2009;41(7):1510-1530. doi:10.1249/MSS.0b013e3181a0c95c

64. Wilkinson SB, Phillips SM, Atherton PJ, et al. Differential effects of resistance and endurance exercise in the fed state on signalling molecule phosphorylation and protein synthesis in human muscle. J Physiol. 2008;586(15):3701-3717. doi:10.1113/jphysiol.2008. 153916

65. Philipson TJ, Snider JT, Lakdawalla DN, Stryckman B, Goldman DP. Impact of oral nutritional supplementation on hospital outcomes. Am J Manag Care. 2013;19(2):121-128.

66. Kim PL, Staron RS, Phillips SM. Fasted-state skeletal muscle protein synthesis after resistance exercise is altered with training. J Physiol. 2005;568(Pt 1):283-290. doi:10.1113/ jphysiol.2005.093708

67. American Thoracic Society. ATS/ACCP statement on cardiopulmonary exercise testing. Am J Respir Crit Care Med. 2003;167 (2):211-277. doi:10.1164/rccm.167.2.211

68. Reilly DF, McNeely MJ, Doerner D, et al. Self-reported exercise tolerance and the risk of serious perioperative complications. Arch Intern Med. 1999;159(18):2185-2192. doi:10.1001/archinte.159. 18.2185

69. Jefford M, Karahalios E, Pollard A, et al. Survivorship issues following treatment completion-results from focus groups with Australian cancer survivors and health professionals. J Cancer Surviv. 2008;2(1):20-32. doi:10.1007/s11764-008-0043-4

70. Rosenberger PH, Jokl P, Ickovics J. Psychosocial factors and surgical outcomes: an evidence-based literature review. $\mathrm{J} \mathrm{Am}$ Acad Orthop Surg. 2006;14(7):397-405. doi:10.5435/00124635200607000-00002

71. Mavros MN, Athanasiou S, Gkegkes ID, Polyzos KA, Peppas G, Falagas ME. Do psychological variables affect early surgical recovery? PLoS One. 2011;6(5):e20306. doi:10.1371/journal. pone.0020306

72. Kitagawa R, Yasui-Furukori N, Tsushima T, Kaneko S, Fukuda I. Depression increases the length of hospitalization for patients undergoing thoracic surgery: a preliminary study. Psychosomatics. 2011;52(5):428-432. doi:10.1016/j.psym.2011. 03.010 
73. DiMatteo MR, Lepper HS, Croghan TW. Depression is a risk factor for noncompliance with medical treatment: meta-analysis of the effects of anxiety and depression on patient adherence. Arch Intern Med. 2000;160(14):2101-2107. doi:10.1001/ archinte.160.14.2101

74. Mitchell AJ, Ferguson DW, Gill J, Paul J, Symonds P. Depression and anxiety in long-term cancer survivors compared with spouses and healthy controls: a systematic review and meta-analysis. Lancet Oncol. 2013;14(8):721-732. doi:10.1016/S1470-2045(13) 70244-4

75. Versteegden DPA, Buise MP, Nienhuijs SW. Shift towards older bariatric patients. Obes Surg. 2018;28(2):555-556. doi:10.1007/ s11695-017-3039-1

76. Karthikesalingam A, Holt PJ, Vidal-Diez A, et al. Mortality from ruptured abdominal aortic aneurysms: clinical lessons from a comparison of outcomes in England and the USA. Lancet. 2014;383(9921):963-969. doi:10.1016/S0140-6736(14)60109-4

77. Pol RA, Zeebregts CJ, van Sterkenburg SM, Reijnen MM. Thirtyday outcome and quality of life after endovascular abdominal aortic aneurysm repair in octogenarians based on the Endurant Stent Graft Natural Selection Global Postmarket Registry (ENGAGE). J Vasc Surg. 2012;56(1):27-35. doi:10.1016/j. jvs.2011.12.080

78. Visser L, Pol RA, Tielliu IF, van den Dungen JJ, Zeebregts CJ. A limited and customized follow-up seems justified after endovascular abdominal aneurysm repair in octogenarians. J Vasc Surg. 2014;59(5):1232-1240. doi:10.1016/j.jvs.2013.11.070

79. Asrar U1 Haq M, Goh CY, Levinger I, Wong C, Hare DL. Clinical utility of exercise training in heart failure with reduced and preserved ejection fraction. Clin Med Insights Cardiol. 2015;9:1-9. doi:10.4137/CMC.S21372

80. Moonesinghe SR, Harris S, Mythen MG, et al. Survival after postoperative morbidity: a longitudinal observational cohort study. Br J Anaesth. 2014;113(6):977-984. doi:10.1093/bja/ aeu224

81. Baillot A, Mampuya W, Comeau E, Meziat-Burdin A, Langlois M. Feasibility and impacts of supervised exercise training in subjects with obesity awaiting bariatric surgery: a pilot study. Obes Surg. 2013;23(7):882-891. doi:10.1007/s11695-0130875-5

82. Funderburk JA, Callis S. Aquatic intervention effect on quality of life prior to obesity surgery: a pilot study. Annu Ther Recreation. 2010;18:66-78.

83. Hickey MS, Gavigan KE, McGammon MR. Effects of 7 days of exercise training on insulin action in morbidly obese men. Clin Exerc Physiol. 1999;1:24-28.

84. Marcon ER, Gus I, Neumann CR. Impact of a minimum program of supervised exercises in the cardiometabolic risk in patients with morbid obesity. Arq Bras Endocrinol Metabol. 2011;55:331-338. doi:10.1590/S0004-27302011000500006

85. Bond DS, Vithiananthan S, Thomas JG, et al. Bari-active: a randomized controlled trial of a preoperative intervention to increase physical activity in bariatric surgery patients. Surg Obes Relat Dis. 2015;11(1):169-177. doi:10.1016/j.soard.2014.07.010

86. Marcon ER, Baglioni S, Bittencourt L, Lopes CL, Neumann CR, Trindade MR. What is the best treatment before bariatric surgery? Exercise, Exercise and Group Therapy, or Conventional Waiting: a randomized controlled trial. Obes Surg. 2017;27(3):763-773.

87. Bond DS, Phelan S, Wolfe LG, et al. Becoming physically active after bariatric surgery is associated with improved weight loss and health-related quality of life. Obesity. 2009;17(1):78-83. doi:10.1038/oby.2008.501

88. Bond D. Bari-active: a preoperative intervention to increase physical activity. Obes Surg. 2011;21(8):1042. doi:10.1007/s11695010-0204-1
89. Stegen S, Derave W, Calders P, Van Laethem C, Pattyn P. Physical fitness in morbidly obese patients: effect of gastric bypass surgery and exercise training. Obes Surg. 2011;21 (1):61-70. doi:10.1007/s11695-009-0045-y

90. Castello-Simoes V, Polaquini Simoes R, Beltrame T, et al. Effects of aerobic exercise training on variability and heart rate kinetic during submaximal exercise after gastric bypass surgery-a randomized controlled trial. Disabil Rehabil. 2013;35(4):334-342. doi:10.3109/09638288.2012.694575

91. Shah M, Snell PG, Rao S, et al. High-volume exercise program in obese bariatric surgery patients: a randomized, controlled trial. Obesity (Silver Spring). 2011;19(9):1826-1834. doi:10.1038/ oby. 2011.172

92. Berggren JR, Boyle KE, Chapman WH, Houmard JA. Skeletal muscle lipid oxidation and obesity: influence of weight loss and exercise. Am J Physiol Endocrinol Metab. 2008;294(4):E726E732. doi:10.1152/ajpendo.00354.2007

93. Marc-Hernandez A, Ruiz-Tovar J, Aracil A, Guillen S, MoyaRamon M. Effects of a high-intensity exercise program on weight regain and cardio-metabolic profile after 3 years of bariatric surgery: a randomized trial. Sci Rep. 2020;10(1):3123. doi:10.1038/s41598-020-60044-z

94. Ouellette KA, Mabey JG, Eisenman PA, et al. Physical activity patterns among individuals before and soon after bariatric surgery. Obes Surg. 2020;30(2):416-422. doi:10.1007/s11695019-04186-8

95. Nguyen N, Champion JK, Ponce J, et al. A review of unmet needs in obesity management. Obes Surg. 2012;22(6):956-966. doi:10.1007/s11695-012-0634-z

96. Villa-Gonzalez E, Barranco-Ruiz Y, Rodriguez-Perez MA, et al. Supervised exercise following bariatric surgery in morbid obese adults: CERT-based exercise study protocol of the EFIBAR randomised controlled trial. BMC Surg. 2019;19(1):127. doi:10.1186/s12893-019-0566-9

97. Soriano-Maldonado A, Martinez-Forte S, Ferrer-Marquez M, et al. Physical Exercise following bariatric surgery in women with morbid obesity: study protocol clinical trial (SPIRIT compliant). Medicine. 2020;99(12):e19427. doi:10.1097/ MD.0000000000019427

98. Bergmark C, Dewan A, Orsoni A. A novel function of lipoprotein [a] as a preferential carrier of oxidized phospholipids in human plasma. J Lipid Res. 2008;49:2230-2239. doi:10.1194/jlr. M800174-JLR200

99. Ahmadi N, Tsimikas S, Hajsadeghi F. Relation of oxidative biomarkers, vascular dysfunction, and progression of coronary artery calcium. Am J Cardiol. 2010;105:459-466. doi:10.1016/j. amjcard.2009.09.052

100. Ahmadi N, Eshaghian S, Huizenga R, Sosnin K, Ebrahimi R, Siegel R. Effects of intense exercise and moderate caloric restriction on cardiovascular risk factors and inflammation. Am J Med. 2011;124(10):978-982. doi:10.1016/j.amjmed.2011.02.032

101. Taylor AJ, Villines TC, Stanek EJ. Extended-release niacin or ezetimibe and carotid intima-media thickness. $N$ Engl J Med. 2009;361:2113-2122. doi:10.1056/NEJMoa0907569

102. Stiegler P, Cunliffe A. The role of diet and exercise for the maintenance of fat-free mass and resting metabolic rate during weight loss. Sports Med. 2006;36:239-262. doi:10.2165/ 00007256-200636030-00005

103. Chaston TB, Dixon JB, O'Brien PE. Changes in fat-free mass during significant weight loss: a systematic review. Int $J$ Obes (Lond). 2007;31:743-750. doi:10.1038/sj.ijo.0803483

104. Webster JD, Hesp R, Garrow JS. The composition of excess weight in obese women estimated by body density, total body water and total body potassium. Hum Nutr Clin Nutr. 1984;38 (4):299-306. 
105. Maffiuletti NA, Jubeau M, Munzinger U. Differences in quadriceps muscle strength and fatigue between lean and obese subjects. Eur J Appl Physiol. 2007;101:51-59. doi:10.1007/ s00421-007-0471-2

106. Blimkie CJ, Sale DG, Bar-Or O. Voluntary strength, evoked twitch contractile properties and motor unit activation of knee extensors in obese and non-obese adolescent males. Eur J Appl Physiol Occup Physiol. 1990;61:313-318. doi:10.1007/BF00357619
107. Pescatello LS, Kelsey BK, Price TB. The muscle strength and size response to upper arm, unilateral resistance training among adults who are overweight and obese. J Strength Cond Res. 2007;21:307-313. doi:10.1519/R-22236.1

108. Hulens M, Vansant G, Lysens R, Claessens AL, Muls E, Brumagne S. Study of differences in peripheral muscle strength of lean versus obese women: an allometric approach. Int J Obes Relat Metab Disord. 2001;25:676-681. doi:10.1038/sj.ijo.0801560

\section{Publish your work in this journal}

Diabetes, Metabolic Syndrome and Obesity: Targets and Therapy is an international, peer-reviewed open-access journal committed to the rapid publication of the latest laboratory and clinical findings in the fields of diabetes, metabolic syndrome and obesity research. Original research, review, case reports, hypothesis formation, expert opinion and commentaries are all considered for publication. The manuscript management system is completely online and includes a very quick and fair peer-review system, which is all easy to use. Visit http://www.dovepress.com/testimonials.php to read real quotes from published authors. 